\title{
UNDERSTANDING THE GENRE FEATURES OF QUALITATIVE RESEARCH: A CASE STUDY
}

\author{
Yi-Huey Guo \\ Foreign Languages \& Literature Department, \\ Tunghai University, Taichung, Taiwan \\ E-mail: guoyh11@thu.edu.tw
}

Received: 15 September 2019

Accepted: 07 October 2019

\begin{abstract}
Some researchers' prejudiced attitude on qualitative research as nonscientific research seems to hinder the development of qualitative research in some Asian social science research communities. Nevertheless, the present study on a qualitative novice's writing process found that the lowly formulaic style of qualitative research writing could be another reason that impedes such development as well. Novice researchers' writing tends to follow model-imitation, which contradicts the lowly formulaic style of qualitative research writing. With the employment of a social approach on writing studies as the theoretical framework, this study treated academic writing as an activity influenced by the writer's situated research community. The writer's varied research attempts in thesis writing process such as the formulation of research questions, employment of research methods, interpretation of research results, and the like, were treated as his/her composing acts. By longitudinally observing one graduate student's use of qualitative research in his thesis proposal writing process, the present study discussed the multifaceted nature of qualitative research and the need of teaching/learning qualitative research as a specific genre in academic writing. Related genre elements to be included in teaching qualitative research are addressed.
\end{abstract}

Keywords: case study research, English for specific purposes, genre analysis, qualitative research, writing studies.

\section{Introduction}

Compared with mainstream researchers' preference for quantitative research, researchers doing a purely qualitative research like ethnography or single case study research in some Asia's social science research communities receive less support (Flowerdew, 1999). Some Asian researchers consider the time-consuming and laborintensive process of qualitative research writing to be the factors discouraging them from doing it (Kuo, 2009); however, Flowerdew (1999) had found another affected factor; that is, the researcher's underdeveloped interpretive writing skills in English. Their lack of proficiency in using English language comfortably for interpretative writing somehow results in their preference for doing quantitative research.

Most novice researchers learn qualitative research as a research method; however, in transforming naturalistic data into words, the students are actually engaged in the process of writing. Studying their research processes means to study their writing processes. Learning how their writing attempts are complicated by the multifaceted nature of 
qualitative research will help us to understand how they write qualitatively. In light of this, this study employed a social approach in writing studies to observe the qualitative research writing process of one Taiwanese graduate student majoring in English education. By analyzing this student's attempts to approach naturalistic data and to transform them into analytical patterns for thesis use, this study discussed how the lowly-formulaic style of qualitative research writing may toughen a qualitative novice's writing process. The results are to shed light on the following issues: (1) to conclude that learning qualitative research as a research method may not suffice a qualitative novice's writing; (2) to highlight the need of treating/teaching qualitative research as a specific academic genre, particularly to those with limited interpretative writing skills.

\section{Literature Review}

\subsection{Thesis Writing as Genre Practice}

The term "genres" was defined by Hyland (2007) as "dynamic constructs" that weave together "individual purposes and wider social and cultural practices" (p. 172-173). Within this framework, thesis writing is a form of genre practice in that most postgraduate students' goals are to obtain their postgraduate degrees through a series of academic genre practices. Among these practices, thesis writing is a common and major one. Having students familiarize themselves with "conventional surface features" (Hyland, 2007, p.173) of thesis writing has been regarded as an essential task. A postgraduate thesis and a research article share similar conventional surface features, both of which are divided sequentially into the section of introduction, methodology, results, discussion, and conclusion (Donesch-Jezo, 2010; Hsiao \& Yu, 2012). Each section tends to be treated as a subgenre as it carries specific rhetorical purposes. Singh (2011) defined them as follows: in the introduction section, the researcher introduces his/her research aims and objectivities by treating this section as "a point of departure" or a "mechanism" (Singh, 2011, p.1024); in the literature review section, the researcher establishes disciplinary arguments through substantial review of prior studies; in the methodology section, the researcher proves "the validity, reliability and the feasibility" of the study (p.1024); in the results and discussion section, the researcher creates a space to present the research findings as "highlighted manner" (p.1024); in the conclusion section, the researcher "closes" the study with "deductions," "findings," "aims," and "objectives" (p.1024). Empirical studies on thesis writing often feature the analysis of a selective subgenre such as the abstract writing (Ning, 2008; Ren and Li, 2011), introduction writing (Kwan, 2006; Rubio, 2011), literature review writing (Hsiao and Yu, 2012; Kwan, 2006; Sler-Monreal and Gil-Salom, 2011), discussion writing (Ali and Nafiseh, 2011), or the acknowledgement writing (Zhao and Jiang, 2010). To examine the research subjects' rhetorical movies in thesis writing, these prior studies largely drew on Swales' (1990) CARS (Creating a Research Space) model, Bhatia's (1993) four-move model, Kwan's (2006) three-move model, or Young and Allison's (2003) seven movestructure model. These move models were developed for a closer look the "conventional discursive structure of the text and appropriate linguistic items" (Donesch-Jezo, 2010, p.230).

\subsection{Writing Qualitatively as a Genre}

The subgenres of thesis have been largely studied yet little research effort was devoted to the line of qualitative research writing as a genre practice. This may be caused by the reason that qualitative research is taught as a research method (not as a genre). In fact, 
qualitative research writing contains the conventional surface features of an academic genre even though the exhibition of these features is less formulaic.

Although the same set of qualitative data may be coded and interpreted differently across researchers, qualitative researchers cannot exempt themselves from not following the research tradition. They still need to choose the study, collect data, and analyze data. The process of qualitative research writing meets Hyland's definition of academic genre that it is a "social action designed to accomplish socially recognised purposes... framed within the institutional processes of the academic world" (Hyland, 2007, p. 173). A discussion of the ontological, epistemological, and methodological characteristics of qualitative research supports the proposed claim of this study that qualitative research writing is a genre practice.

Given its "phenomenological/interpretivist paradigm" nature (Arghode, 2012, p.155), qualitative research draws on the belief that "reality cannot be comprehended as it is constantly shaped through social interactions" (Arghode, 2012, p. 162). Qualitative researchers collect data and analyze them to better understand existing realities (Arghode, 2012). They seek the ontological meaning of their studies by uncovering the research participants' life experiences (Arghode, 2012, p. 158), show the epistemological meaning by giving the observed phenomena their interpretations (Arghode, 2012, p. 158), and adhere to the methodological meaning by means of observational and interview data (Arghode, 2012, p. 159). Within "the institutional process of the academic world" (Hyland, 2007, p. 173), qualitative research is written to "convenience peers to assent to a knowledge claim" (Hyland, 2007, p.12).

\subsection{The Multifaceted Nature of Qualitative Research Writing}

Qualitative researchers believe that social constructs should be "interpreted" rather than "measured" (Johnson \& Waterfield, 2004), so they understand the time and efforts spent on data collection/analysis. Its nature is multifaceted (Chenail, Duffy, George, \& Wulff 2011) as it is a naturalistic, descriptive, inductive, process-oriented, and meaning-making design (Bogdan \& Biklen, 2007). This nature results in a lowly-formulaic writing style, in which the researcher is expected to demonstrate good interpretative writing skills in interpreting the observed phenomenon. Unfortunately, this somehow complicates a novice's writing of it.

Some students struggle with the identification of "salient features" (Chenail, 2011) in reading massive textual chunks of qualitative data and some students consider it a formidable writing task to establish patterns for an analytical discussion. Kuo (2009) pointed out that what prevents some postgraduate students from doing qualitative research is not the collection of data but the writing of its epistemological and methodological elements. Its lack of a standardized writing pattern makes its stylistics a lowly-formulaic one. More specifically, it can stand alone as a single method and can be used conjointly with quantitative research as a mixed-method approach (Bitsch, 2005). Next, it can be used for the development of theory, the evaluation of policy, or the interpretation of any research issues (Bitsch, 2005). Furthermore, different from the manipulation of variables for generalizable results in quantitative research, there is minimal manipulation of variables in qualitative research (Goussinsky, Reshef, Yanay-Ventura, \& Yassour-Brorchowitz, 2011). Instead of establishing representativeness, qualitative researchers write to unravel "the dynamic, holistic and individual aspects of the human experience" (Vivar, McQueen, Whyte, \& Armayor, 2007, p. 64), so they pay closer attention to the "situational representativeness" found on particular individuals rather than to the "demographic representativeness" found 
on sample at large (Horsburgh, p. 311). Lastly, qualitative writing is researcher-centered (Johnson \& Waterfield, 2004) so that the same set of data can be developed into different patterns for the discussion of varied issues. The aforementioned features could become writing blocks to researchers with poor interpretive writing skills since they may find qualitative research writing too lowly-formulaic; some may even regard it subjective or unscientific.

\section{Research Method}

Inspired by Casanave's (2010) study on the qualitative research writing experiences of three Japanese doctoral students, this study investigated the qualitative research writing process of one graduate student - Lin (pseudonym). In this study, the term "writing" is emphasized; a conceptual scheme based on the perspective of writing studies allows this study to treat Lin's research attempts as composing acts. The study employed Hyland's (2007) social approach that treats academic writing as a "situated and indexical" (p.6) activity influenced by the writer's situated research community. Lin's varied research attempts including the formulation of research questions, employment of research methods, interpretation of research results, etc. were treated as his composing acts. It is aimed for understanding how his qualitative research writing was influenced by his situated research environment and the lowly-formulaic nature of qualitative research.

Lin was a graduate student majoring in English education at one Taiwanese university. Students in his program were required to complete their master theses in English for the qualification for the masters' degree. Their master theses consisted of the following chapters: introduction, literature review, research methodology, results, discussion, and conclusion. Upon hearing from a mutual acquaintance that Lin was planning to conduct qualitative research for his thesis study, the researcher approached him and asked his permission to allow the researcher to observe his writing process. He agreed to participate in this study voluntarily. According to him, he was the only student conducting qualitative research in his program during the course of study. Lin's initial plan was to conduct a questionnaire research on English major undergraduate students' motivation for learning English. However, his plan was turned down by the professors he approached due to the fact that similar topics had been widely studied so that his research idea was a stale one. He eventually approached one teacher with qualitative research expertise, and she agreed to supervise his thesis research. According to his advisor, Lin's qualitative research knowledge was limited in spite of his claim that he had taken research methods courses and acquired fundamental knowledge about qualitative research.

Despite his interest in English-majored undergraduates' learning motivation, his research plan was vague. He did not know what to investigate specifically and did not follow traditional research procedure by starting from the review of literature. Instead, he chose a top-down approach by going to the research site directly for data collection. He held that a clearer idea could emerge after collecting some on-site data.

Thanks to his introverted personality, he failed to find voluntary research participants. Through his advisor's help, two sophomores studying in the undergraduate program of Lin's school agreed to be his research participants voluntarily. These two participants were taking the same English composition course. This aroused Lin's interest in observing their writing motivation. Hence, he observed their class participation, collected their writing assignments, and interviewed them, through which he found that a composition on teacher's written feedback had a great impact on the students' motivation for English writing. 
The study was based on one-year-long observation of Lin's thesis proposal drafting, starting from the time he began his fieldwork till the time he told the researcher that he could not make further progress toward his thesis writing and had to withdraw from participating in this study. In fact, he struggled with revising his second draft of literature review chapter and research methodology chapter. Although he said to his advisor that more time would be needed for his completion of revision, no further revisions were made. Eventually, he told his advisor that he decided to put aside his thesis proposal writing in order to take more courses for the reinforcement of discipline-specific knowledge. This caused the data collection of this study to come to a halt, so the analysis was based on his data collection and composing acts. Despite the "halt," findings gained out of Lin's case has allowed us to have a glimpse of possible challenges faced by a qualitative novice in the writing process.

Given the ethnographic nature of this study, "pre-established research questions" were not made. "Key issues" developed out of collected data were used to guide the study instead (Flowerdew, 2000, p. 128). Throughout observing Lin's research attempts (i.e., his ways of approaching data naturalistically and analyzing them inductively), the following key issues were addressed: first, the influence of Lin's situated research environment and the lowlyformulaic nature of qualitative research on his qualitative research writing; second, what Lin may need in terms of learning qualitative research as a specific genre; third, genre elements essentially important to qualitative research writing. The first key issue was presented in the Result section and the latter two in the Discussion section.

The data consisted of the following sources: (a) Lin's thesis proposal drafts; (b) his thesis advisor's written feedback of his drafts; (c) three semi-structured interviews with him; (d) one semi-structured interview with one of his former teachers; (e) two unstructured interviews with his advisor. As stated earlier, he was unable to complete the required three proposal chapters. He did not draft the introduction chapter; nevertheless, he finished two drafts of the literature review chapter and two drafts of the research methodology chapter. He composed the proposal section by section by emailing each section's draft to his advisor and revised it based on the advisor's feedback. After finishing the revision, he emailed back the revised draft for further feedback. Such revision process continued until his thesis supervisor was satisfied with his writing quality.

The interviews with Lin were to know his development of qualitative research writing strategies. The researcher interviewed one of Lin's course instructors to know how his qualitative research writing might be affected by the situated research environment and interviewed his advisor twice to know how she reviewed Lin's thesis proposal quality. All the data were conducted in Mandarin Chinese but were transcribed verbatim and translated into English. The length of the interviews ranged from 20 to 40 minutes. All the data were compared/contrasted and triangulated for a fuller understanding of the studied phenomenon.

Due to the qualitative nature of this study, the data were analyzed qualitatively. It emphasizes the process of Lin's progression into a qualitative research community. It is also concerned about a particular context that can only be understood through the investigation of its being (Bogdan \& Biklen, 2007). The analysis is framed by viewing writing as an activity situated in "textual knowledge and practices" and in "a variety of contextual forces" (Kamberelis \& Luna, 2004, p. 239). This study (1) explores the type(s) of textual knowledge and contextual forces received by Lin during these practices and (2) discusses how his 
writing reflects the influence of these forces. The objective is to understand whether or not learning qualitative research as a research method could suffice a novice's writing of it.

\section{Results}

\subsection{The Influence of Contextual Forces}

Most faculty members in Lin's program specialized in quantitative research design; therefore, the instructional emphases were on quantitative research. Qualitative research was treated as the supplement or vignette to quantitative analysis. According to Lin, "they (the professors) only recommended some qualitative researchers' articles and asked us to read by ourselves."

As a result, the professors' favoured research methods had a great influence on the students' selection of methodological design: Most of his classmates conducted quantitative research for their theses research. The commonest type of research method selected by his peers was the questionnaire research. Some students not intended to do questionnaire research would also be recommended by their advisors to conduct questionnaire research since it would be less time- and energy-consuming.

\subsection{The Challenge of Approaching Data Naturalistically}

Lin's thesis data consisted of the following sources: four semi-structured interviews, two classroom observations, two teacher-student writing conferences, and four pieces of writing samples provided by his research participants. Except the collected writing samples, other data were recorded and transcribed verbatim. In his eyes, conducting interviews was the most labour-intensive task and interpreting the participants' written data (i.e., their composition assignments) the most challenging one.

He held that his interviewees' unrelated responses to the interview questions affected his data quality. "Sometimes they failed to express their opinions clearly, causing me the need to elaborate more background information to make sense of my questions," he said. Since his research participants were undergraduate students studying in the same school as him, they treated Lin like a peer and less like a researcher. Because of that, the interviews easily turned to informal chats. In his first interview with one of the interviewees, it took him four hours to finish because the interviewee was interested in graduate study and thus kept asking Lin related questions.

Of particular note is his failure to interpret the participants' writing samples. Although he collected a number of writing samples from them, he did not know how to utilize them as data. His thesis supervisor provided him with two possible solutions: One was to interview the participants about the content, length, persona, or voice of writing in writing these composition pieces; another was to use them as props to illustrate how the participants' writing content, length, persona, or voice reflected their writing motivation. Unfortunately, he considered it hard. Henceforth, his advisor addressed the concerns: First, if he had no idea about the use of these writing samples as data, he needed to reconsider whether it was still worthy of including them as "data" since his thesis committee members might question his research purpose. Next, if he chose to discard the collected writing samples, he might be questioned for a lack of analysis about the participants' writing since his study was about their English writing motivation. Unfortunately, until the end of this study, no further improvement was made pertaining to his use of collected writing samples as data. 


\subsection{The Challenge of Writing Qualitatively}

Lin began his thesis proposal drafting from drafting the research methodology chapter first. This writing behaviour was influenced by his prior course experiences. One of his course instructors told them that "writing the methodology section is the easiest; writing the introduction and literature review is harder and more complicated." Although Lin considered writing the chapter of research methodology an easier task, the first draft of his research methodology did not meet his advisor's satisfaction, particularly the part of data analysis procedure. The following excerpt shows the writing of his data analysis procedure.

\section{Excerpt 1}

\section{Data analysis procedure}

Huberman and Miles (1994) suggest three processes in qualitative data analysis, (1) data reduction, (2) data display, and (3) conclusion drawing and verification. In this study, this approach of analysis will be adopted. Contextual analysis will be applied to collected writing pieces to confirm interview data.

As shown in Excerpt 1, he used technical terms (such as "data reduction," "data display," "conclusion drawing and verification," and "contextual analysis") to show his adherence to qualitative research discourse. However, he failed to explain specifically his utilization of these terms so that he received the following comment (Excerpt 2) from the advisor.

\section{Excerpt 2}

This part of description is too vague. What do you mean by contextual analysis? Also, what do you plan to do with the so-called data reduction and data display? You need to rewrite this part. Didn't you say earlier that you already had a theoretical framework that can be used for the motivation research? You said that people doing motivation research usually employ that motivation model for data analysis. You can introduce and explain that motivation model. Did you read the qualitative research book that discusses data coding? You can cite the book's data coding concept to your data analysis. I attach one writing sample from one journal for your reference. After reading this sample piece, you may have clearer ideas about writing your data analysis.

Lin later submitted the second draft yet he left the part of data analysis procedure unrevised. In his second draft shown below, he wrote something different instead. According to him, he searched several published full-length research articles for extensive reading in addition to the sample his advisor attached. Unfortunately, this attempt did not work as effectively as he expected.

Excerpt 3

\section{Data analysis procedure:}

In this part, I want to wait until I finish reading the qualitative research textbook, because I'm not familiar with the qualitative analysis procedures, and all the journals I've read didn't provide detailed description on this part.

\section{Discussion}

Lin's immersion in a quantitative research-centered research environment had affected his selection of methodological approaches, implying a local research community's need of accepting multifaceted academic discourses for the development of research paradigms. Other forms of methodological approaches should be valued more by his situated research 
environment in addition to the mainstream use of quantitative and mixed-method approach. Novice researchers' awareness of academic discourse diversity should be enhanced since not all language research is aimed for establishing representativeness. When the following situations apply, the students should be encouraged to try qualitative research: first, when the purpose of their research is to understand a phenomenon performed by a particular group of people; second, when the purpose of their research is to revise the existing theory or to establish a new theory (Vivar, McQueen, Whyte, \& Armayor, 2007, p. 64).

Compared with his failure to analyze data qualitatively, collecting data seemed to be a self-solvable task to him since he could maintain the interviews in consistency when the interviewees drifted into another discussion. His failure to analyze collected documents seemed to imply that establishing patterns out of collected written data for an analytical discussion of the participants' writing behaviour or writing process was a challenge in his research process. In qualitative literacy research, written documents are often used to make sense of other data, which are useful sources for data triangulation. If he failed to code and interpret this part of data, they were merely "collectibles." Theoretically, his collected writing samples together with other forms of data (e.g., the interviews, observational field notes, and the recorded teacher-student writing conferences) should be coded and compared/contrasted, through which analytical patterns would be developed for discussing the affected factors of his participants' English writing motivation.

His failure to correlate varied sources of data for meaning-making implies the lowlyformulaic nature of qualitative research writing as an affected factor for his development of writing plan. The lowly-formulaic style of qualitative research writing gave him the impression that writing qualitatively was writing abstract concepts. The inductive nature of qualitative data coding appeared abstract to him. The occurrence of this may accord with the fact that novice writers tend to find analyzing abstract concepts a challenging task (Huckin, 2004). Qualitative researchers often draw on an inductive method for the establishment of theories/paradigms instead of following a deductive approach that relies on established theories/paradigms to ground the study (Gibson, 2008, p.206). Developing "key issues" for interpreting the meaning of observed phenomena (Flowerdew, 2000) should be highlighted in teaching Lin during his collecting of data. His case reflected the "intertextual influence" (Bazerman, 2004) caused partially by the research environment in which he was immersed. The inductive style of qualitative research writing was less applicable to him as he was unclear how to shift from specific to general for the reification of research findings and the identification of key issues. The inductive nature of qualitative research contradicted his pre-existing research behaviour, which toughened his qualitative research process at some aspects.

Lin's case shows that teaching qualitative research merely as a research method may result in a novice's unawareness of "rhetorical situations" (Miller, 1984) in the writing process. As shown earlier, Lin was unable to see the original 'situations' emerging in his research plan and the new 'situations' emerging in the research context that required his correlation, incorporation, and articulation of various data sources in the actual production of qualitative research paper. This may be partly caused by his reliance on "model-imitation" (Tran, 2007) as the main writing strategy, in which he wrote by following prior researchers' work as the writing model. Unfortunately, such imitation behaviour contradicted the lowlyformulaic style of qualitative research writing. To reinforce his ability in lowly-formulaic style of writing, this study suggests the need of an intensive learning of the following qualitative research writing skills: (1) learning the ontologically-driven and methodologically-driven 
rhetorical situations existing in the data, (2) learning to identify salient features of these rhetorical situations. (3) learning to raise key issues out of the salient features of data, (4) learning to support the key issues with the use of selective data as props for "thick description" use in the Result section, (5) learning to support the key issues with selective literature as props in the Discussion section, (6) learning to reformulate the key issues into the form of research questions and to place them formally in the Research Questions section for the fit of thesis convention. Ontologically-driven rhetorical situations here refer to coding data based on the themes, scenes, or the persona of the observed phenomenon; methodological-driven rhetorical situations refer to Vivar, McQueen, Whyte, \& Armayor's (2007) seventeen steps of qualitative research process, ranging from the background of the study to the limitations of the study for the "move" of a qualitative research. These seventeen steps include "(1) selecting an interesting topic; (2) introducing the background to the problem; (3) presenting the significance of the study; (4) defining the concepts; (5) establishing the research aim(s); (6) deciding on the research paradigm; (7) finding a theoretical framework; (8) choosing the data collection method; (9) planning the data collection; (10) describing the procedure of data analysis; (11) enhancing the quality of the data; (12) reporting the ethical issues; (13) presenting the limitations of the study; (14) disseminating the findings; (15) planning the time frame; (16) concluding; (17) presenting the references" (Vivar, McQueen, Whyte, \& Armayor, 2007, p.61-62). The above sequence may not completely follow the traditional procedure of thesis writing (e.g., coding/analzying the data prior to making the research questions) due to the inductive nature of qualitative research writing. However, an awareness of these may allow Lin to gain analytical ability instead of only being able to "structure a study around a hypothesis or narrow questions" (Bogdan \& Biklen, 2006, p. 272).

Treating Lin's qualitative research writing as a genre practice may assist his interpretive writing of the epistemological elements. This study suggests the inclusion of genre elements in students' practice of qualitative research writing (e.g., coding, cross-case comparison, inductive reasoning, key issue defining, and narrative writing). More instructional emphasis needs to be placed on training students to seek "salient patterns" and "interestingness" (Barton, 2004) in reading qualitative research articles. With their development of genre knowledge, the quality of their qualitative research writing could also be developed.

One more thing to be noted is Lin's reliance on interviews as the main data source, which indicates a need to train him to be the "research instrument" (Kvale, 1996, p.147) for the maximization of research findings since he failed to vary the use of multiple data sources. If he could become a research instrument, he could conduct quality interviews and use them to make sense of other data. In fact, his attempts to maintain the interviews in unity had implied the researcher-manipulative nature of interview data: regardless of structured or semi-structured interviews, the nature of interview data is researcher-manipulative allowing the researcher to determine the research plan. Collected documents are established texts made by the participants and are thus participant-manipulative per se, which may toughen Lin's writing. To solve the problem of interpreting participant-manipulative data, Lin, an interviewer as well as a researcher, should be trained to know: (1) to make his interviewing purposes clear to the interviewees; (2) to familiarize himself with the rhetorical purposes of his interview questions; (3) to correlate the interview questions to the research questions. Namely, before meeting the interviewee, he should have known "what to ask and how"; during the interview, he should know "which aspects of a subject's answer to follow" (Kvale, 1996, p. 147); after the interview, he should have clear ideas about "which answers to 
interpret" (p. 147). Decades ago, Kvale (1996) divided interview questions into nine types based on their rhetorical purposes, including "introducing questions," "follow-up questions," "probing questions," "specifying questions," "direct questions," "indirect questions," "structuring questions," "silence," and "interpreting questions" (p. 133-135). If used appropriately, quality interview data could be information-rich to assist Lin in making sense of other data.

\section{Conclusion}

This study draws on the factual situation that the development of qualitative research in some research communities is somewhat tardy. The researcher calls readers' attention to this problem by examining the qualitative research writing process of Lin, who was in the stage of writing his thesis proposal. The lowly-formulaic nature of qualitative research has resulted in his failure to write qualitatively. Although this study came to a standstill to his failure to make further achievements in thesis writing, his writing journey had shed light on some lessons. To sum up, first, there is a need to teach a qualitative research method course as a specific genre to qualitative novices like Lin, who not only had limited interpretative writing skills but was immersed in a research community where doing qualitative research received less support. This study discusses related genre elements to be highlighted in the instruction. A reinforcement of these genre elements may assist his development of qualitative research writing ability. Second, there is a need to develop/reinforce Lin's interviewing skills as interviewing seems to be the data that he can operate with his ability level. Training him to be a skilled interviewer as a research instrument seems to be an attainable goal for the time being since quality interview data will allow him to maximize his analysis of findings.

This study seeks to understand Lin's qualitative research process from the perspective of writing studies. The suggestions made contribute to our understanding of how the nature of qualitative research writing may complicate a novice's interpretation of qualitative data. However, there are also limitations of the study. First, as a single case study research, the research purpose is not on establishing representativeness but on what we learn from the case; therefore, the findings are not generalizable. Second, the collection of data, due to Lin's failed writing attempt, was forced to come to a standstill, which also limits our further understanding of his thesis writing practice. For future research, this study suggests researchers highlight the students' practice of each aforementioned qualitative genre element for further investigation.

\section{References}

Arghode, V. (2012). Qualitative and quantitative: Paradigmatic differences. Global Education Journal, 4, 155-163.

Bhatia, V. K. (1993). Analyzing genre: Language use in professional setting. London and New York: London Group.

Barton, E. (2004). Linguistic discourse analysis: How the language in texts works. In Bazerman, C. \& Prior, P. (Eds.). What writing does and how it does it (pp.57-82). Mahwah, NJ: Lawrence Erlbaum.

Bazerman, C. (2004). Intertextuality. How texts rely on other texts. In Bazerman, C. \& Prior, P. (Eds.). What writing does and how it does it (pp.83-96). Mahwah, NJ: Lawrence Erlbaum. 
Bitsch, V. (2005). Qualitative research: A grounded theory example and evaluation criteria. Journal of Agribusiness, 23(1), 75-91.

Bogdan, R. \& Biklen, S.K. (2007). Qualitative research for education: An introduction to theories and methods. ( $5^{\text {th }}$ ed.) Boston, MA: Pearson Education/Allyn and Bacon.

Casanave, C.P. (2010). Taking risks?: A case study of three doctoral students writing qualitative dissertations at an American university in Japan, Journal of Second Language Writing, 19(1), 1-16.

Chenail, R., Duffy, M., George, S., \& Wulff, D. (2011). Facilitating coherence across qualitative research papers. The Qualitative Report, 16(1), 263-275.

Chenail, R. (2011). Learning to appraise the quality of qualitative research articles: A contextualized learning object for constructing knowledge. The Qualitative Report, 16 (1), 236-248.

Donesch-Jezo, E. (2010). Academic genre analysis: teaching academic discourse writing to medical university students. The International Journal of Learning, 17(7), 229-242.

Flowerdew, J. (1999). Problems in writing for scholarly publication in English: The case of Hong Kong. Journal of Second Language Writing, 8(3), 243-264.

Flowerdew, J. (2000). Discourse community, legitimate peripheral participation, and the nonnative-English-speaking scholar. TESOL Quarterly, 34(1), 127-150.

Gibson, K. (2008). Analogy in scientific argumentation. Technical Communication Quarterly, $17(2), 202-219$.

Goussinsky, R., Reshef, A., Yanay-Ventura, G. \& Yassour-Brorchowitz, D. (2011). Teaching qualitative research for human services students: A three-phase model. The Qualitative Report, 16(1), 126-146.

Horsburgh, D. (2003). Evaluation of qualitative research. Journal of Clinical Nursing, 12(2), 307-312.

Hsiao, C. \& Yu, H. (2012). Knowledge presentation in thesis writing - Examining move use in reviewing literature. English Teaching and Learning, 36(3), 133-179.

Huckin, T. (2004). Content analysis: What texts talk about. In Bazerman, C. \& Prior, P. (Eds.). What writing does and how it does it (pp.13-32). Mahwah, NJ: Lawrence Erlbaum.

Hyland, K. (2007). Disciplinary discourses: Social interactions in academic writing. Ann Arbor, MI: The University of Michigan Press.

Johnson, R., \& Waterfield, J. (2004). Making words count: the value of qualitative research. Physiotherapy Research International, 9(3), 121-131.

Kamberelis, G. \& Luna, L. (2004). Children's writing: How textual forms, contextual forces, and textual politics co-emerge. In Bazerman, C. \& Prior, P. (Eds.). What writing does and how it does it (pp.239-278). Mahwah, NJ: Lawrence Erlbaum.

Kuo, Y. (2009, January). Directing and chairing EFL doctoral students' qualitative research dissertations in Taiwan. Paper presented at the First Philippine International English Language Conference, Manila, Philippine.

Kwan, B. (2006). The Schematic structure of literature reviews in doctoral theses of applied linguistics. English for Specific Purposes, 25, 30-55.

Kvale, S. (1996). Interviews: An introduction to qualitative research interviewing. Thousand Oaks, CA: Sage Publications.

Miller, C. (1984). Genre as social action. Quarterly Journal of Speech. 70, 151-67.

Ning, Z. (2008). A genre-based analysis of English research article abstracts and the linguistic feature of personal pronouns for financial economics. US-China Education Review, $5(7), 62-65$. 
Ren, H. \& Li, Y. (2011). A comparison study on the rhetorical moves of abstracts in published research articles and master's foreign-language theses. English Language Teaching, 4(1), 162-166.

Rubio, M. (2011). A pragmatic approach to the macro-structure and metadiscoursal features of research article introductions in the field of agricultural sciences. English for Specific Purposes, 30(4), 258-271.

Singh, S. (2011). An intervention to assist students with writing their dissertations and theses. South African journal of Higher Education, 25(5), 1020-1030.

Soler-Monreal, C. \& Gil-Salmom, L. (2011). A cross-language study on citation practice in PhD theses. International Journal of English Studies, 11(2), 53-75.

Swales, J. M. (1990). Genre analysis: English in academic and research settings. Cambridge, UK: Cambridge University Press.

Tran, L.T. (2007). Learners' motivation and identity in the Vietnamese EFL writing classroom. English Teaching Practice \& Critique, 6(1), 151-163.

Vivar, C., McQueen, A., Whyte, D., \& Armayor, N. (2007). Getting started with qualitative research: developing a research proposal. Nurse Researcher, 14(3), 60-73.

Yang, R. \& Allison, D. (2003). Research articles in applied linguistics: Moving from results to conclusions. English for Specific Purposes, 22, 365-385.

Zhao, M. \& Jiang, Y. (2010). Dissertation acknowledgements: Generic structure and linguistic features. Chinese Journal of Applied Linguistics, 33(1), 94-109. 